\title{
A Scientific Approach of using the DMAIC Methodology to Investigate the Effect of Cutting Tool Life on Product Quality and Process Economics
}

\author{
A Case Study of a Saudi Manufacturing Plant
}

\author{
Ahmed Baha Eddine Aichouni \\ Razak Faculty of Technology and Informatics \\ University Technology Malaysia \\ Kuala Lumpur, Malaysia \\ baha1995@graduate.utm.my
}

\author{
Haslaile Abdullah \\ Razak Faculty of Technology and Informatics \\ University Technology Malaysia \\ Kuala Lumpur, Malaysia \\ haslaile.k1@utm.my
}

\author{
Faizir Ramlie \\ Razak Faculty of Technology and Informatics \\ University Technology Malaysia \\ Kuala Lumpur, Malaysia \\ faizir.k1@utm.my
}

\begin{abstract}
One of the major priorities for manufacturing companies in the globalized economy is the ability to offer highquality products to customers at the lowest production cost. Globally, process improvement methods and techniques are used to reduce waste and improve product and service quality. This paper aims to propose a systematic model based on process improvement methodologies and tools to help the manufacturing companies decide on cutting tool life and other manufacturing issues. This research seeks to prove that some common industry practices, such as changing cutting tools in machining processes, can significantly affect the economics of production and the overall performance of the plant. The research is mainly based on analyzing real field data using the DMAIC methodology to identify improvements in order to achieve a balance between economy and quality in a Saudi manufacturing plant. Although the study was concerned only with changing cutting tools in the machining process in an air conditioning plant, its findings and conclusions can be generalized to all manufacturing processes.
\end{abstract}

Keywords-manufacturing process improvement; DMAIC methodology; cutting tool life; machining operations

\section{INTRODUCTION}

In many industries such as the automotive, the military, and the Heat, Ventilation, and Air Conditioning (HVAC) industries, metal cutting and machining are heavily utilized in the manufacturing processes. The US Cutting Tool Institute (USCTI) reported data showing that cutting tool market was worth $\$ 2.2$ billion on January $2020[1,2]$. The cutting-tool consumption is usually considered an indicator of manufacturing activity in a specific industry, as those cutting tools represent a primary consumable element in many manufacturing processes. The consumption of cutting tools can be used as a leading indicator of the manufacturing activity, as it measures actual production levels in the manufacturing plant [2]. Cutting-tool wear and consumption are considered subjects of major concern $[2,3]$. This is of major importance for air conditioning manufacturers and military industries in Saudi Arabia, which has invested heavily in such industries within its 2030 Saudi Vision $[4,5,6,18]$. It is estimated that the size of Saudi investments in the HVAC manufacturing sector stood at $\$ 3.7$ billion in 2018 and is projected to grow up to reach $\$ 7.1$ billion by 2024 [7].

According to [1], cutting-tool life and tool wear is of practical importance in manufacturing companies. Cutting tools are used to cut materials to parts as they pass throughout the machining processes. Naturally, the quality of the cutting tools will be affected by the modifications on the metal to form appropriate pieces. According to the results of previous studies in this field, the operating conditions and the state of the cutting tools are critical for ensuring the balance between production cost and quality of the final product $[2,3,8]$. The common practice in manufacturing processes when replacing cutting tools is to be based on the experience of the machinist or the operator. It is obvious that this practice has several implications on the process itself from an economic point of view [8]. Therefore, the need to develop a more scientific approach to determine the frequency of tool replacement and the optimum 
replacement time is a major concern in the industry [1]. For this reason, many approaches from different perspectives have been reported $[1,2,3,8]$.

The study presented in [2] proposed a cutting tool resource management model based on CAM programming and the principles of lean manufacturing. The proposed model was shown to be suitable for increased productivity and cost reduction in machining, through an increased Material Removal Rate (MRR), and maximized cutting tool utilization. The presented algorithm was adequate for efficient selection of cutting variables for maximum MRR, maximum tool utilization, minimum machining cost, and reduced waste in the manufacturing process. Furthermore, the model permitted the estimation of aspects related to manufacturing process sustainability in terms of energy use, $\mathrm{CO}_{2}$-footprint, and water consumption. Recently, a study conducted on the reliability of cutting tools developed a stochastic cutting tool life model that helps to determine the most economic tool replacement time [8]. Also, it investigated high-pressure cooling and showed that this practice can help making the machining process more efficient and more robust. Interestingly, the research demonstrated how statistical tools can be adequately used to perform a reliability analysis and spot improvement opportunities in the manufacturing process. It was suggested that this approach needs to be tested and validated under real manufacturing conditions.

The importance of developing and adopting a scientific method for replacing worn-out cutting tools for CNC machines in a US automotive factory was studied in [3]. It was noted that the actual practice of replacing the worn-out cutting tools was based on the experience of the machining operators. This practice has several limitations since it leads to two extreme situations. The cutting tools were being either underutilized or over-utilized. In both cases, cost-effectiveness and product quality were heavily affected. The proposed method was based on the use of Statistical Process Control (SPC) techniques to monitor the cutting tool wear in the production system through measurements of the dimensions of the produced parts. The methodology used was based on the monitoring of the quality characteristic using variable control charts $(\overline{\mathrm{X}}-\mathrm{R}$ and $\overline{\mathrm{X}}-\mathrm{s})$ and process capability analysis. The author suggested that the occurrence of out of statistical control situations in the control charts indicate that the cutting tool is worn out and needs to be replaced in the machining process. It was also shown that this SPC-based approach can be used by manufacturing companies in other industrial sectors to cut costs and produce high-quality products according to design specifications. Other studies developed methods based on SPC charts to investigate the stability of manufacturing processes and their capability to meet the design specifications [9, 10]. The DMAIC Six Sigma methodology associated with the use of the seven basic quality tools, was successfully implemented in different industrial settings to reduce defects and to achieve sustainable improvement in process performance [11-15].

The objective of the paper is to propose a systematic model based on process improvement methodologies and tools to help manufacturing companies in the decision making concerning the cutting-tool life and other manufacturing issues. This study aims to investigate the effect of the cutting tool life in machining processes on the quality of the manufactured products and the production economics.

\section{Methodology}

An extensive literature review was performed and indicated that a large number of process improvement methodologies are available for manufacturing [16]. The study showed that the PDCA and the six sigma DMAIC methodologies present superior performance in problem-solving and process improvement compared to other improvement models. The DMAIC methodology uses statistics and process improvement tools to locate and solve existing problems and improve processes. The goal of the DMAIC process is to implement long-term solutions to current problems in manufacturing. The use of the DMAIC methodology helps to identify, eliminate, and control issues of product quality and production process that may arise [17]. The Six Sigma DMAIC (Define, Measure, Analyze, Improve, and Control) methodology is used in this research. The problem is defined in the first step. Furthermore, it is important to recognize and define the critical stages in the process. The measure phase involves measuring the key process characteristics and quantifying the problem through data collection and analytics. The purpose of the analysis phase is to identify the root causes of the problem and propose solutions. The two remaining phases, i.e. implement and control, concern the implementation of the proposed improvements and the control and monitoring of the process. Control ensures maintaining the solution and its results and sustaining the gains achieved. Monitoring leads to sustainable improvements and guarantees long-term success. Permanent monitoring is therefore required $[11,13]$.

\section{RESULTS AND DISCUSSION}

This section presents the results of the data analysis of the process data, using the DMAIC methodology. The data collected from the manufacturing process at the HVAC plant are presented in Table I. These variables are believed to measure the problem of the use of cutting tools and their effect on the quality of the final product (produced parts). The following sections provide a complete description of the implementation of the DMAIC methodology in the study of the research problem and in order to make improvement proposals.

TABLE I. PROCESS DATA AND RESEARCH VARIABLES

\begin{tabular}{|c|c|}
\hline $\begin{array}{c}\text { Process } \\
\text { variables }\end{array}$ & Definition \\
\hline X factor & $\begin{array}{c}\text { Tool life measured in terms of number of produced parts } \\
\text { per change during the period from June to October, } \\
2018 .\end{array}$ \\
\hline Y factor & Produced part characteristics and design specification \\
(product quality).
\end{tabular}

\section{A. Step One: Define}

The first step of the DMAIC methodology starts by defining the problem and identifying the objectives to be achieved. The current project was performed in a HVAC manufacturing company, which produces a variety of products mainly for heat ventilation and air conditioning systems. Their 
main products range from small AC units for domestic and office use, to big chillers for industrial and commercial plants. The company serves as a supplier of manufactured parts to other industries, especially in the military sector. It was noted that the plant suffered from the problem of high consumption of cutting tools during production. Therefore, the need to develop a scientific approach to investigate this problem and determine the root causes of the problem emerged.

\section{B. Step Two: Measure}

This step consists of measuring the extent of the problem in the manufacturing process. The analyzed process data are the number of manufactured parts by each cutting tool. Operations are referred in this case to the use of specific cutting tools to produce a number of produced parts. Figure 1 shows the variation of the numbers of produced parts for each cutting tool change. It can be seen that there is a big variability in the number of manufactured parts by each cutting tool. Table II shows the basic statistics of the manufacturing data, which show the number of units produced during the study period for all operations.

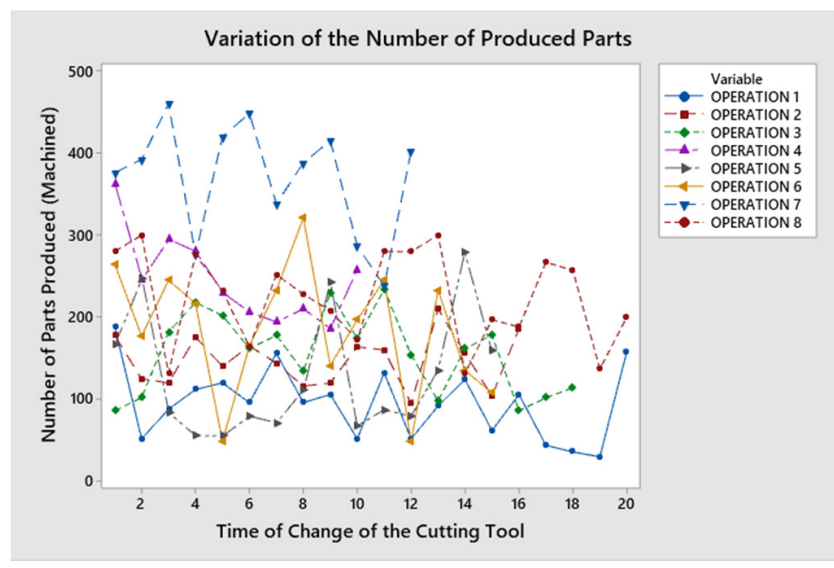

Fig. 1. Variation of the number of produced parts by each cutting tool.

TABLE II. BASIC STATISTICS OF THE MANUFACTURING DATA

\begin{tabular}{|c|c|c|c|c|c|}
\hline $\begin{array}{c}\text { Operation / } \\
\text { cutting tool }\end{array}$ & Mean & StDev & Min & Max & Change \\
\hline Operation 1 & 95 & 44.07 & 30 & 189 & $630 \%$ \\
\hline Operation 2 & 147 & 32.32 & 95 & 210 & $221 \%$ \\
\hline Operation 3 & 155 & 49.0 & 86 & 234 & $272 \%$ \\
\hline Operation 4 & 246 & 54.4 & 186 & 362 & $195 \%$ \\
\hline Operation 5 & 127 & 75.2 & 55 & 279 & $507 \%$ \\
\hline Operation 6 & 185 & 78.2 & 49 & 321 & $655 \%$ \\
\hline Operation 7 & 370 & 70.5 & 238 & 460 & $193 \%$ \\
\hline Operation 8 & 224 & 56.7 & 132 & 300 & $227 \%$ \\
\cline { 5 - 6 } & & & & Average & $\mathbf{3 6 3 \%}$ \\
\hline
\end{tabular}

It can be seen that there are large discrepancies and differences in the number of units produced for each cutting tool. The variations range from a percentage of $193 \%$ to a maximum of $655 \%$, with an average of $363 \%$ as a percentage of the difference between production operations for each cutting tool. The differences between production operations for each cutting tool are shown in Figure 2. Such an observation would be clear evidence of the validity of the problem statement, as it is clear that there is variability in the cuttingtool life as measured by the number of the manufactured parts. This may have a significant effect on product quality in terms of process stability and capability, and the economy of the manufacturing process. This early conclusion will be verified in the following sections.

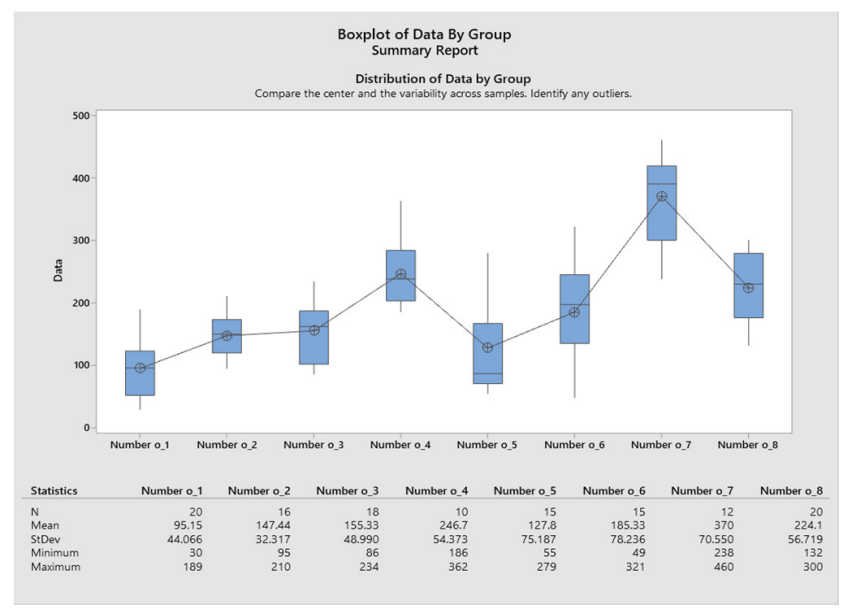

Fig. 2. Box plot of the distribution of the number of produced parts for all operations

\section{Step Three: Analyze}

At this phase, the objective is to investigate the data to find the causes of the problem and propose solutions and improvements. The focus is to take advantage of the analyzed data in order to investigate the effect of the variability in the machined parts by each cutting tool on the quality of these machined parts as final products. For that purpose, the dimensional characteristics for the machined parts were obtained with their specifications. Data samples were obtained for periods where at least two or three cutting tool changes were made.

\section{1) Process Stability Analysis}

To investigate the consistency of the manufacturing process concerning product characteristics, SPC control charts $(\bar{X}-\mathrm{s}$ charts) were used. Figure 3 shows that the process was statistically stable in some cases (1 st, 2nd, 3rd, 5th, 7th, and 8th operation), and out of statistical control in other cases (4th and 6 th operation). This indicates the existence of special causes affecting the manufacturing process. These special causes of variation should be investigated to improve the production process.

\section{2) Process Capability Analysis}

Process capability analysis was performed to test the manufacturing process's capability to produce parts that meet the design specifications. The data collected from the process allowed conducting a study of the production operation's capability to meet the specification by comparing the dimensions of the produced units with the design specifications. Figure 4 shows the results of the capability analysis for two operations. The results show that the production operations $2,3,4,5$, and 8 could achieve the design 
specifications. On the other hand, operations 1, 6, and 7) were not capable of achieving the specifications. This conclusion can be obtained from Table III, which shows the process capability indices $\left(\mathrm{C}_{\mathrm{p}}, \mathrm{C}_{\mathrm{pk}}\right)$ for each operation in the production processes. Capability indices $\mathrm{C}_{\mathrm{p}}, \mathrm{C}_{\mathrm{pu}}, \mathrm{C}_{\mathrm{pL}}$, and $\mathrm{C}_{\mathrm{pK}}$ greater or equal than 1 indicate that the process was capable to meet the design specifications.

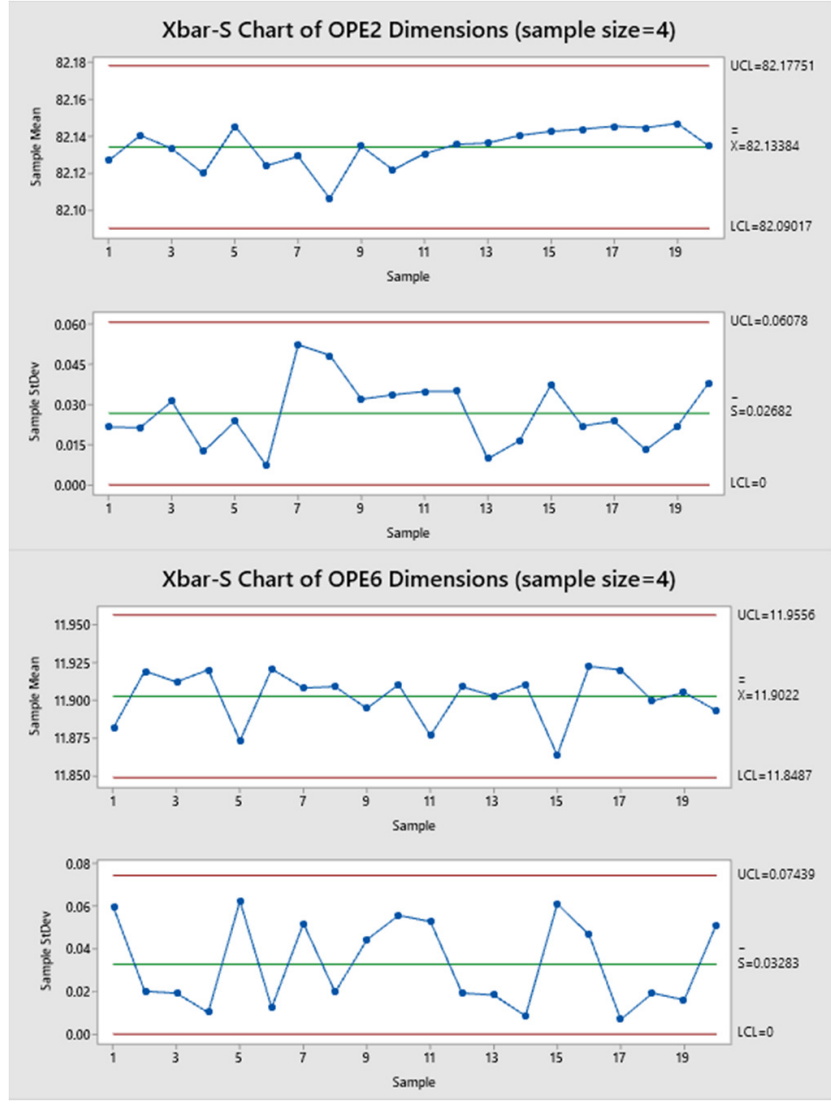

Fig. 3. Control charts for two operations (cutting tool type).

\section{3) Cutting Tool Life and Product Quality Relationship}

In this section, a summary of the previous analysis is presented to identify the nature of the effect of the cutting tool's life on the production process in terms of its stability and capability to meet the product design specifications. Figures 5 and 6 show the nature of the relationship between the factors of capability $\left(\mathrm{C}_{\mathrm{p}}, \mathrm{C}_{\mathrm{pk}}\right)$ and the statistical values (average, highest value, and lowest value) of the produced parts. The data show that using the cutting tool at a lower rate to produce small quantities and reduce the period of use does not necessarily lead to production according to the design specifications. The use of the cutting tool for long periods does not affect the process's capability to produce according to the specifications. This manufacturing process remains under the influence of special causes underlying the process elements $(5 \mathrm{Ms}$ and $\mathrm{E}$ : Manpower, Machine, Measurement, Material, Methods, and Environment). This can be investigated using cause and effect analysis.

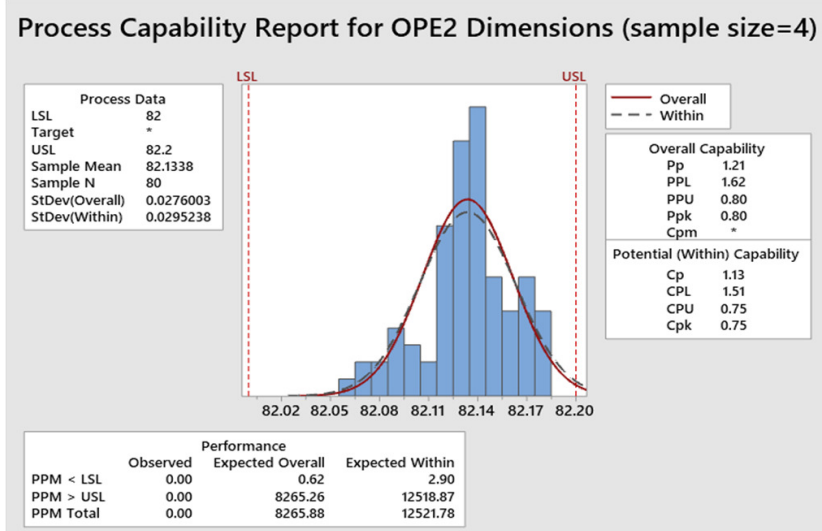

The actual process spread is represented by 6 sigma.

Process Capability Report for OPE6 Dimensions (sample size=4)

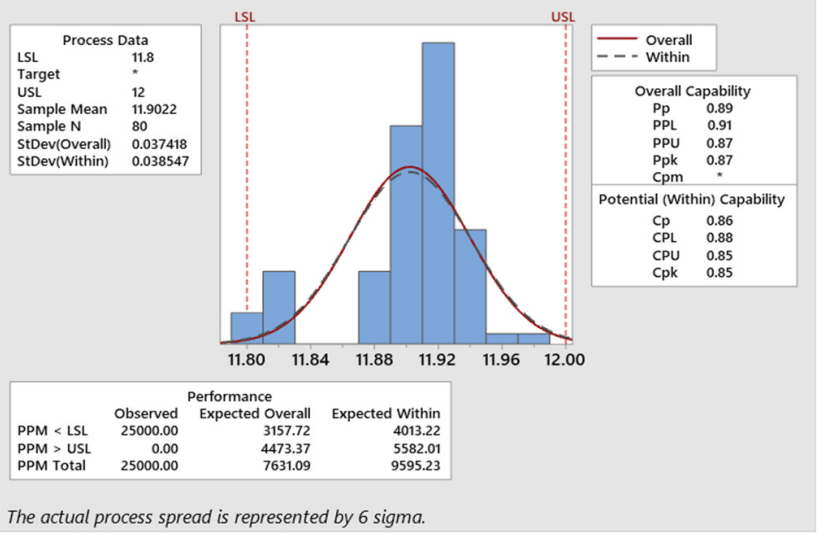

Fig. 4. Process capability analysis for two operations.

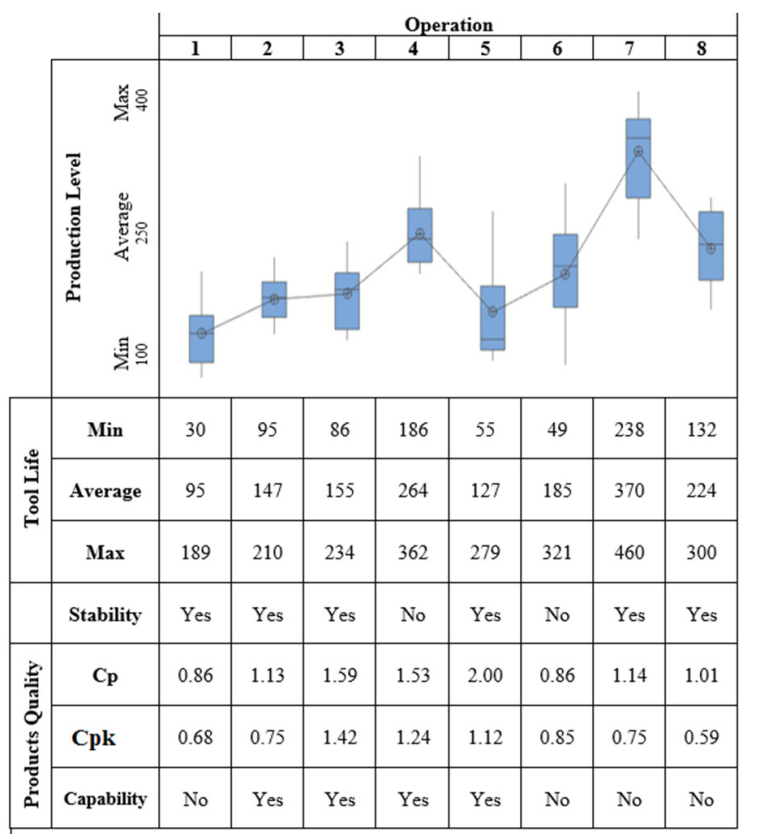

Fig. 5. Summary of cutting tools life analysis and production quality. 
TABLE III. CAPABILITY INDICES

\begin{tabular}{|c|c|c|c|c|c|c|c|c|}
\hline Operation & $\mathbf{1}$ & $\mathbf{2}$ & $\mathbf{3}$ & $\mathbf{4}$ & $\mathbf{5}$ & $\mathbf{6}$ & $\mathbf{7}$ & $\mathbf{8}$ \\
\hline $\mathbf{C}_{\mathbf{p}}$ & 0.86 & 1.13 & 1.59 & 1.53 & 2.00 & 0.86 & 1.14 & 1.01 \\
\hline $\mathbf{C}_{\mathbf{p k}}$ & 0.68 & 0.75 & 1.42 & 1.24 & 1.12 & 0.85 & 0.75 & 0.59 \\
\hline $\begin{array}{c}\text { Overall capability } \\
\text { status }\end{array}$ & NO & YES & YES & YES & YES & NO & NO & NO \\
\hline
\end{tabular}

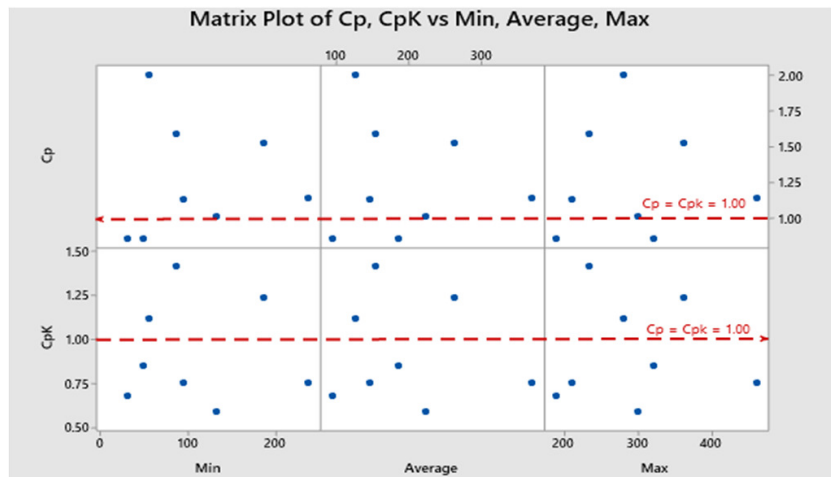

Fig. 6. Correlation between capability indices and the statistical values for cutting tool life.

\section{4) Cause and Effect Analysis}

The previous analysis revealed that the manufacturing process is under the influence of special causes. In some cases, its capability to achieve design specifications in the final product is rather weak. The causes of the variability in the cutting tool life should be investigated further. For that purpose, root cause analysis was performed using the cause and effect diagram (Ishikawa diagram). Electronic brainstorming sessions were conducted with the company's quality department, including technicians working in the production line and employees from other departments. This was the most suitable method during the COVID-19 pandemic situation. Experts in machining processes from academia and industry were consulted during these sessions.

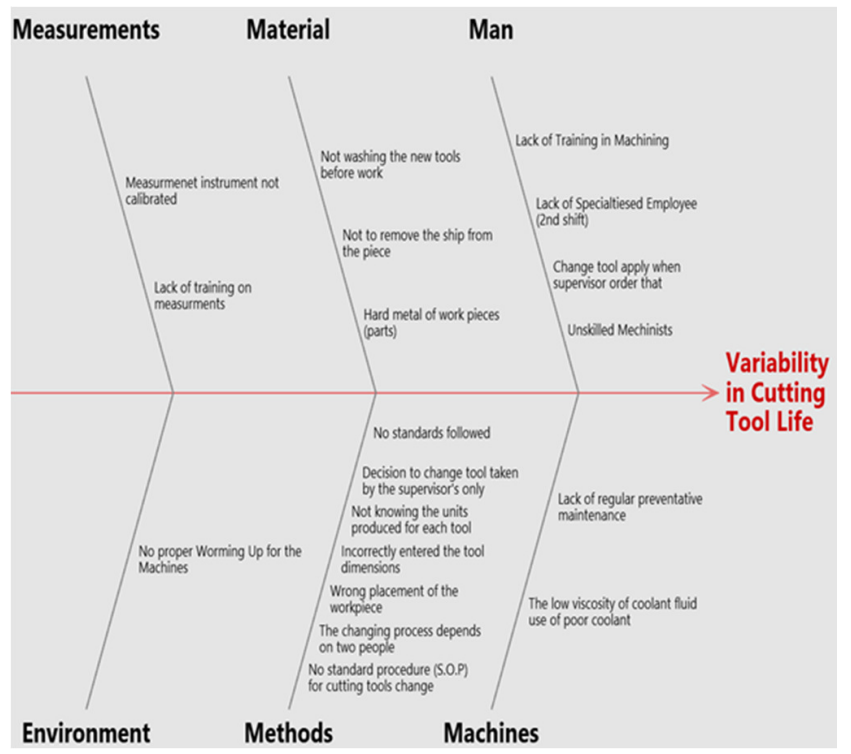

Fig. 7. Ishikawa diagram for the variability of the cutting tool.
Figure 7 presents the results of the cause and effect analysis. The most important causes of the problem from the point of view of the company's employees and machine operators are summarized in the Figure.

\section{Step Four: Improve}

Based on the root causes analysis, another brainstorming session was performed to identify the most important causes and suggest appropriate solutions. A researcher guided the discussion based on world-class manufacturers' good manufacturing practices [7]. A root cause analysis tree was used to manage each category's proposed solutions (5M and $\mathrm{E}$ ). This analysis contributes to the organization of the selection of solutions and facilitates the process of prioritizing them. Figure 8 shows the problems and the suggested solutions.

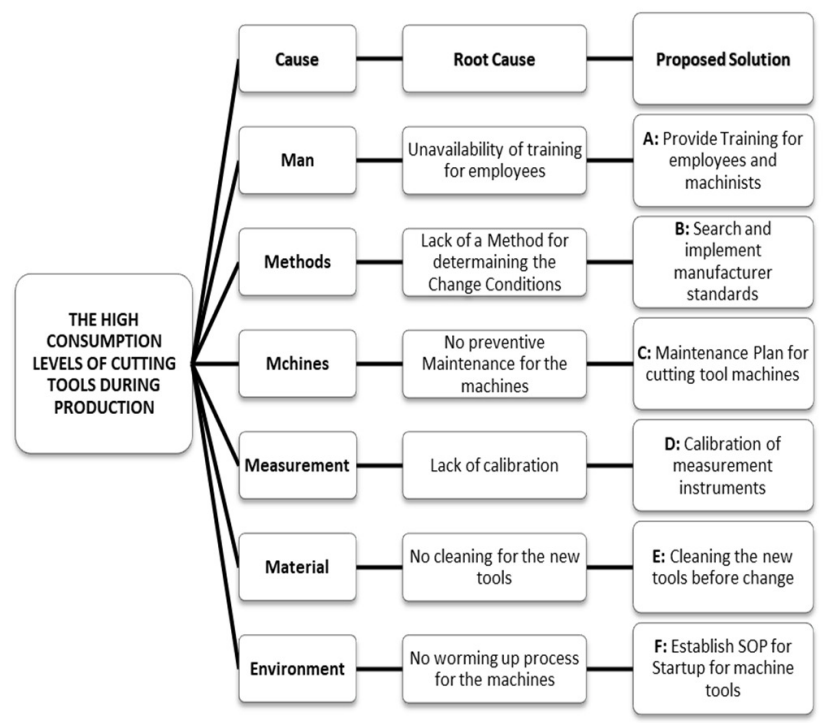

Fig. 8. Root cause analysis tree.

Following the root cause analysis and in order to formulate an action plan to improve the process, the solution selection matrix was used. This stage was done through brainstorming sessions that included all stakeholders, managers, and decisionmakers to further participate in the implementation plan. The selection matrix (also known as a priority matrix) was used to evaluate problems and the proposed solutions for each problem or potential preparations based on specific criteria which can be based on time effect, cost effect, and other factors. Table IV represents the analytical approach proposed to help the management implement solutions to solve the high consumption of cutting tools and thus reduce subsequent manufacturing costs. Through the proposed solution matrix, certain weights have been determined for each of the evaluation criteria. Thus, the result of the matrix in arranging solutions is:

- The manufacturer standards had the highest weight in the solution matrix with a $19 \%$ importance. This was a proposed solution for the lack of a method for determining the change conditions. Consequently, from this point, it can 
be concluded that the research problem was a major concern for the company.

- Training provision for the employees was an anticipated solution. This was the second selected solution with an $18 \%$ importance.

- Preventive maintenance can be used as an effective solution for the problem of cutting tool life in manufacturing since it helps manufacturing operators to avoid major failures that result in the replacement and change of tools [19].

- Calibration of measurement instruments and machine startup procedures were among other suggested solutions.

TABLE IV. SELECTION MATRIX (PRIORITY MATRIX)

\begin{tabular}{|c|c|c|c|c|c|c|c|}
\hline Solution & C1 & C2 & C3 & C4 & C5 & Total & Percentage \\
\hline $\begin{array}{c}\text { Solution A: } \\
\text { Provide training for } \\
\text { employees and } \\
\text { machinists }\end{array}$ & 8 & 8 & 5 & 1 & 2 & 24 & $18 \%$ \\
\hline $\begin{array}{c}\text { Solution B: } \\
\text { Search and implement } \\
\text { manufacturer standards }\end{array}$ & 7 & 5 & 2 & 5 & 6 & 25 & $19 \%$ \\
\hline $\begin{array}{c}\text { Solution C: } \\
\text { Maintenance plans for } \\
\text { cutting tool machines }\end{array}$ & 4 & 5 & 6 & 5 & 2 & 22 & $17 \%$ \\
\hline $\begin{array}{c}\text { Solution D: } \\
\text { Calibration of } \\
\text { measurement instruments }\end{array}$ & 3 & 5 & 3 & 4 & 5 & 20 & $15 \%$ \\
\hline $\begin{array}{c}\text { Solution E: } \\
\text { Cleaning the new tools } \\
\text { before change }\end{array}$ & 8 & 7 & 2 & 2 & 4 & 23 & $18 \%$ \\
\hline $\begin{array}{c}\text { Solution F: } \\
\text { Establish SOP for start- } \\
\text { up for machine tools }\end{array}$ & 5 & 6 & 5 & 1 & 2 & 17 & $13 \%$ \\
\hline
\end{tabular}

The evaluation criteria: $(1=\mathrm{Bad}, 10=\mathrm{Good})$ : $\mathrm{C} 1$ : Easy to implement, C2: Feasible, C3: Cost effectiveness, C4: Time, C5: Easy to maintain.

\section{E. Step Five: Control}

The control phase of the Six Sigma DMAIC cycle is ideally performed after implementing the proposed solutions. The control phase aims to sustain the improvements achieved through the other stages of the DMAIC cycle. The control phase in DMAIC is about controlling the "vital few" variables, identified during the earlier phases. In the present research, since the proposed solutions were not yet implemented, this phase is not covered.

\section{CONCLUSION}

In the current paper, the DMAIC methodology was implemented in a Saudi manufacturing plant. The main goal was to investigate the high consumption of cutting tools in the machining process and to evaluate its impact in the quality of the machined products. The DMAIC methodology was adopted to find an optimal set of factors that can help the manufacturing plant's leadership optimize the use of the cutting tools and achieve a balance between quality and production economy. Along the five DMAIC phases, different quality tools were implemented in order to identify the root causes of the problem, to develop an action plan to reduce the impact of the problem on the production, and to minimize the process variability. The present manufacturing case study proved that through the application of quality tools, basic tools, and management and planning tools, it was possible to improve company's production processes. The research suggested the implementation of the Six Sigma DMAIC methodology in order to eliminate unproductive stages and operations, and to develop and use the technology to drive improvements in the manufacturing process. Although the study was concerned only with cutting tools life in the machining process in the HVAC plant, the findings and conclusions can be generalized to all manufacturing processes suffering from such problems.

\section{REFERENCES}

[1] F. S. S. Staff 1162, "Cutting Tool Consumption Up 10.8\% Year-toDate," American Machinist, Aug. 13, 2018. https://www.americanmachinist.com/cutting-tools/article/21902825/ cutting-tool-consumption-up-108-yeartodate (accessed Aug. 26, 2020).

[2] A. E. Bonilla Hernández, "On cutting tool resource management," Ph.D. dissertation, University West, Trollhättan, Sweden, 2018.

[3] E. Ferrell, "Analysis of Tool Wear and Tool Life of Cutting Tool Inserts using Statistical Process Control Charts: A Case Study," M.S. thesis, Morehead State University, Morehead, KY, USA, 2017.

[4] A. Al-Harbi, "Performance management framework for research and development activities in Saudi Arabia Oil and Gas Sector," Ph.D. dissertation, Universiti Teknologi Malaysia, Johor, Malaysia, 2016.

[5] S. Al-Otaibi, "The relationship between service and organizational culture on students' satisfaction at UMM-Al-Qura university," Ph.D. dissertation, Universiti Teknologi Malaysia, Johor, Malaysia, 2019.

[6] "Saudi Vision 2030," Vision 2030. https://www.vision2030.gov.sa/en (accessed Jan. 26, 2021).

[7] "Saudi Arabia's \$7+ Billion HVAC/R Market 2014-2024: Competition, Forecast and Opportunities - ResearchAndMarkets.com," Business Wire, May 13, 2019. https://www.businesswire.com/news/home/2019051300 5393/en/Saudi-Arabias-7-Billion-HV ACR-Market-2014-2024 (accessed Jan. 26, 2021).

[8] Ž. Vagnorius, "Reliability of metal cutting tools:: Stochastic tool life modelling and optimization of tool replacement time," Ph.D. dissertation, Norwegian University of Science and Technology, Trondheim, Norway, 2010.

[9] M. H. Doroudyan, A. Asgari, A. Amiri, and M. Bashiri, "Multi-objective Efficient Design of np Control Chart Using Data Envelopment Analysis," International Journal of Engineering, vol. 26, no. 6, pp. 621630, Jun. 2013.

[10] E.-A. Attia, K. Khader, and O. Nada, "Mistake Proofing Cam Mechanism Through Six-sigma Process: Case Study on Clothes Printing Machines," International Journal of Engineering, vol. 32, no. 3, pp. 438-444, Mar. 2019.

[11] S. E. Black, "Using Basic Quality Tools to Improve Production Yields and Product Quality in Manufacturing," M.S. thesis, East Tennessee State University, Johnson City, TN, USA, 2015.

[12] I. Hrvacic, "Design and implementation of SPC systems in defense industry manufacturing process," Periodicals of Engineering and Natural Sciences, vol. 6, no. 1, pp. 27-40, Feb. 2018, https://doi.org/ 10.21533/pen.v6i1.163.

[13] P. Li, P. Jiang, and G. Zhang, "An Enhanced DMAIC Method for Feature-Driven Continuous Quality Improvement for Multi-Stage Machining Processes in One-of-a-Kind and Small-Batch Production," IEEE Access, vol. 7, pp. 32492-32503, 2019, https://doi.org/10.1109/ ACCESS.2019.2900461.

[14] I. Elbadawi, M. Aichouni, and N. A. Messaoudene, "Developing an Innovative and Creative Hands-on Lean Six Sigma Manufacturing Experiments for Engineering Education," Engineering, Technology \& Applied Science Research, vol. 6, no. 6, pp. 1297-1302, Dec. 2016, https://doi.org/10.48084/etasr.838. 
[15] I. A. Memon, A. Ali, M. A. Memon, U. A. Rajput, S. a. K. Abro, and A. A. Memon, "Controlling the Defects of Paint Shop using Seven Quality Control Tools in an Automotive Factory," Engineering, Technology \& Applied Science Research, vol. 9, no. 6, pp. 5062-5065, Dec. 2019, https://doi.org/10.48084/etasr.3160.

[16] A. B. E. Aichouni, F. Ramlie, and H. Abdullah, "Process improvement methodology selection in manufacturing: A literature review perspective," International Journal of Advanced and Applied Sciences, vol. 8, no. 3, pp. 12-20, Mar. 2021, https://doi.org/10.21833/ijaas.2021. 03.002 .

[17] A. Trimarjoko, D. S. Saroso, H. H. Purba, S. Hasibuan, C. Jaqin, and S. Aisyah, "Integration of nominal group technique, Shainin system and DMAIC methods to reduce defective products: A case study of tire manufacturing industry in Indonesia," Management Science Letters, vol. 9, pp. 2421-2432, 2019, https://doi.org/10.5267/j.msl.2019.7.013.

[18] M. Touahmia, M. Aichouni, A. Alghamdi, L. Kolsi, and H. Alzamil, "A Foresight Study about the Skills and Competencies Needed for Quality Professionals in 2030: An Empirical Study of Saudi Arabia," Engineering, Technology \& Applied Science Research, vol. 10, no. 5, pp. 6176-6182, Oct. 2020, https://doi.org/10.48084/etasr.3713.

[19] L. S. Tavassoli, N. Sakhavand, and S. S. Fazeli, "Integrated Preventive Maintenance Scheduling Model with Redundancy for Cutting Tools on a Single Machine," Engineering, Technology \& Applied Science Research, vol. 10, no. 6, pp. 6542-6548, Dec. 2020, https://doi.org/10.48084/etasr. 3903. 